\title{
Descrição de ovos e ninfas de Triatoma klugi (Hemiptera, Reduviidae, Triatominae)
}

\author{
José Jurberg ${ }^{1}$, Helene S. Barbosa ${ }^{2}$, Cleber Galvão ${ }^{3}$, Dayse da S. Rocha ${ }^{1}$ \& Maria Beatriz A. Silva ${ }^{3}$ \\ 1. Laboratório Nacional e Internacional de Referência em Taxonomia de Triatomíneos, Instituto Oswaldo Cruz-Fiocruz, Av. Brasil 4365, \\ 21045-900 Rio de Janeiro, RJ, Brasil. (jjurberg@ioc.fiocruz.br) \\ 2. Laboratório de Biologia Estrutural, Instituto Oswaldo Cruz, Fundação Oswaldo Cruz, Av. Brasil 4365, 21040-361 Rio de Janeiro, RJ, \\ Brasil. \\ 3. Faculdade Nossa Senhora das Graças, Universidade de Pernambuco, Rua Arnóbio Marques, 310, Santo Amaro, Recife, PE, Brasil.
}

\begin{abstract}
Description of eggs and nymphs of Triatoma klugi (Hemiptera, Reduviidae, Triatominae). The authors had described the morphologic characteristics of Triatoma klugi Carcavallo, Jurberg, Lent \& Galvão, 2001 to the group of species belonging to "T. oliveirai complex". Until the moment it has been difficult to separate on the nymphs characteristics basis these species, what it justifies the development of this work. The specimens had been collected in openings of rocks in the Malavok mount in the locality of Linha Brazil, city of Nova Petrópolis, in the State of Rio Grande do Sul. The local of capture of the Triatominae is placed enters 700 and $800 \mathrm{~m}$ of altitud $\left(29^{\circ} 18^{\prime} 38^{\prime \prime} \mathrm{S}, 5^{\circ} 04^{\prime} 57^{\prime \prime} \mathrm{W}\right)$. Together with T. oliveirai (Neiva, Pinto \& Lent, 1939), its morphologically related species, is the only ones of the complex that had not been found, until the moment, in the State of Mato Grosso, Mato Grosso do Sul and Goiás, Brazil. In experimental conditions, already it was tested and proven its susceptibilities to the infection for Trypanosoma cruzi (Chagas, 1909) and Trypanosoma rangeli (Tejera, 1920). The comparative analysis of the ornaments of the exocorium of eggs and of three nymphs of T. klugi by optic microscopy and scanning electron microscopy showed some morphologic particularities, with prominence for: the ventral face of the head, the stridulatory sulcus and the last abdominal segments (IX, X - future genitalia and XI - anal duct). These data contribute for the magnifying of the distinguishing parameters aiming at diagnosis of $T$. klugi during its nymphal development.
\end{abstract}

KEYWORDS. Systematics, taxonomy, morphology, Triatominae, Chagas'disease.

RESUMO. Os autores descreveram as características morfológicas de Triatoma klugi Carcavallo, Jurberg, Lent \& Galvão, 2001 pertencente ao grupo de espécies que compõem o "complexo T. oliveirai". Até o presente tem sido difícil separar essas espécies com base nas características ninfais, o que justifica o desenvolvimento deste trabalho. Os espécimes foram coletados em frestas de rochas no morro Malavok na localidade de Linha Brasil, município de Nova Petrópolis, no Estado do Rio Grande do Sul. O local de captura dos triatomíneos

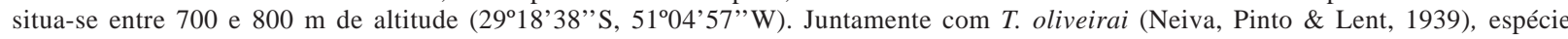
morfologicamente mais próxima, são as únicas do complexo que não foram encontradas, até o momento, no Estado do Mato Grosso, Mato Grosso do Sul e Goiás, Brasil. Em condições experimentais, já foi testada e comprovada a sua susceptibilidade à infecção pelo Trypanosoma cruzi (Chagas, 1909) e Trypanosoma rangeli (Tejera, 1920). A análise comparativa das ornamentações do exocório dos ovos e de três estádios ninfais de T. klugi por microscopia óptica e microscopia eletrônica de varredura mostrou algumas particularidades morfológicas, com destaque para: a face ventral da cabeça, o sulco estridulatório e os últimos segmentos abdominais (IX, X - futura genitália e XI - tubo anal). Esses dados contribuem para a ampliação dos parâmetros diferenciais visando à diagnose de $T$. klugi durante o seu desenvolvimento ninfal.

PALAVRAS-CHAVE. Sistemática, taxonomia, morfologia, Triatominae, doença de Chagas.

Os triatomíneos, vetores da doença de Chagas, pertencem à subfamília Triatominae que atualmente conta com 18 gêneros e 141 espécies. Todas as espécies são transmissoras potenciais de Trypanosoma cruzi (Chagas, 1909), agente etiológico da doença de Chagas. Nem todas as espécies são vetoras efetivas, somente algumas, como por exemplo, Triatoma infestans (Klug, 1834), T. brasiliensis Neiva, 1911 e Panstrongylus megistus (Burmeister, 1835), devido ao seu alto grau de adaptação aos ambientes domésticos e a antropofilia (LENT \& Wygodzinsky, 1979; TonN, 1988; SChofield, 1998; Carcavallo et al., 1998; Mejia et al., 1999; Galvão et al., 2003). De acordo com SHerLock et al. (1998) até o momento, 107 espécies já foram descritas como natural ou experimentalmente infectadas pelo T. cruzi. Esses vetores têm como característica biológica principal, o hematofagismo obrigatório de ambos os sexos e em todas as fases evolutivas (LimA, 1940; JuRBERG \& GALVÃo, 2006). A alimentação sanguínea é fundamental para que os cinco estádios ninfais possam evoluir. Esse fato de fêmeas, machos e ninfas serem hematófagos, agrava o potencial de transmissão do T. cruzi (BRENER \& ANDRADE, 1979).

Triatoma klugi Carcavallo, Jurberg, Lent \& Galvão, 2001 pertence ao "complexo oliveirai" que é composto por seis espécies, todas da região centro-oeste e sul do Brasil: T. oliveirai Neiva, Pinto \& Lent, 1939; T. matogrossensis Leite \& Barbosa, 1953; T. williami Galvão, Souza \& Lima 1965; T. guazu Lent \& Wygozinsky, 1979; T. jurbergi Carcavallo, Galvão \& Lent, 1998 e T. klugi Carcavallo, Jurberg, Lent \& Galvão, 2000.

O estudo pormenorizado de cada táxon torna-se cada dia mais necessário visando compreender a relação filogenética entre as diversas espécies. A taxonomia antes baseada somente na morfologia, hoje conjuga outros caracteres. Assim, espécies que compõem determinados complexos, por apresentarem grandes semelhanças morfológicas na fase adulta, necessitam de outros tipos de abordagens para a caracterização 
morfológica e cromática de ovos, ninfas e adultos (JURBERG et al., 2004).

$\mathrm{O}$ estudo da morfologia de ovos e ninfas tem sido ressaltado por vários autores e considerado de fundamental importância para a taxonomia. Essas abordagens tiveram início em 1935, quando GALLIARD realizou um estudo morfológico comparativo dos ovos de algumas espécies de triatomíneos por microscopia óptica. Mais tarde, Abalos \& Wygodzinsky (1951) estudaram a fauna triatomínica da Argentina, ilustrando ovos e ninfas de Triatoma infestans (Klug, 1834), vistos por meio de microscopia óptica, que foram posteriormente aprimoradas por BARTH \& MuTH (1958). BARATA (1981) observou a ornamentação exocorial de dez espécies do gênero Rhodnius Stål, 1859 por meio de microscopias óptica e eletrônica de varredura e elaborou, a partir dessas características, uma chave dicotômica. Assim, a morfologia de ovos e ninfas de triatomíneos tem sido alvo de estudos de diversos outros autores (CARCAVALLO et al.,1975, 1978; GonÇALVES et al., 1985; JURBERG et al., 1986; MasCARENHAS, 1987; JuRBERG et al., 1991a, b; Costa et al., 1991; JuRBERG \& Vogel, 1994; JuRBERG \& CAMPOS, 1995; Rocha et al., 1996; JuRBERG et al., 1998; GALÍNDEZGirón et al., 1998; SILVA et al., 2000; JURBERG et al., 2002; SiLVA et al., 2005).

As diferenças sexuais entre as ninfas de quinto estádio têm sido outro critério utilizado na distinção dos sexos (EsPínOLA, 1966; Lent \& JuRBERG, 1965, 1969, 1970; Perlowagora-Szumlewicz \& Cruz, 1972; Da Rosa et al., 1992a, b).

A microscopia eletrônica de varredura tem sido uma importante ferramenta na taxonomia, auxiliando na investigação e na análise de estruturas que permitem a diferenciação das espécies. Características morfológicas comparativas de espécies do "complexo oliveirai" têm sido publicadas (SILva et al., 1998, 1999, 2002, 2005), assim como a descrição de ninfas dos cinco estádios e do exocório de ovos por microscopia óptica e eletrônica de varredura (SILVA et al., 2000; JuRBERG et al., 2002; SILVA et al., 2003, 2005). O emprego dessa técnica permite detalhar algumas áreas da anatomia externa dos triatomíneos e possibilita que se estabeleçam novos caracteres com intuito de auxiliar na resolução de problemas sistemáticos dos triatomíneos.

No presente trabalho, as estruturas de ovos de $T$. klugi e do sulco estridulatório, búcula e rostro, dos últimos segmentos abdominais (IX, X - futura genitália e XI) tubo anal, foram comparadas morfologicamente durante o desenvolvimento ninfal por microscopia eletrônica de varredura, com o objetivo de num futuro próximo comparar estruturas, possibilitando o esclarecimento do "status" das espécies crípticas e dos complexos específicos.

\section{MATERIAL E MÉTODOS}

Os exemplares de triatomíneos estudados foram provenientes de colônias aclimatadas desde 2001 no insetário do Laboratório Nacional e Internacional de Referência em Taxonomia de Triatomíneos (LNIRTT) do Instituto Oswaldo Cruz, Rio de Janeiro. Todo material analisado encontra-se depositado na Coleção Rodolfo Carcavallo do LNIRTT do Instituto Oswaldo Cruz (laminário - T. klugi: números 5676 - 5693) (Figs. 1, 2).

Microscopia óptica. Foram utilizados dois ovos e duas ninfas dos cinco estádios. Os ovos tiveram o opérculo destacado e montado entre lâmina e lamínula com fenol. Para análise das ninfas, foram selecionadas as
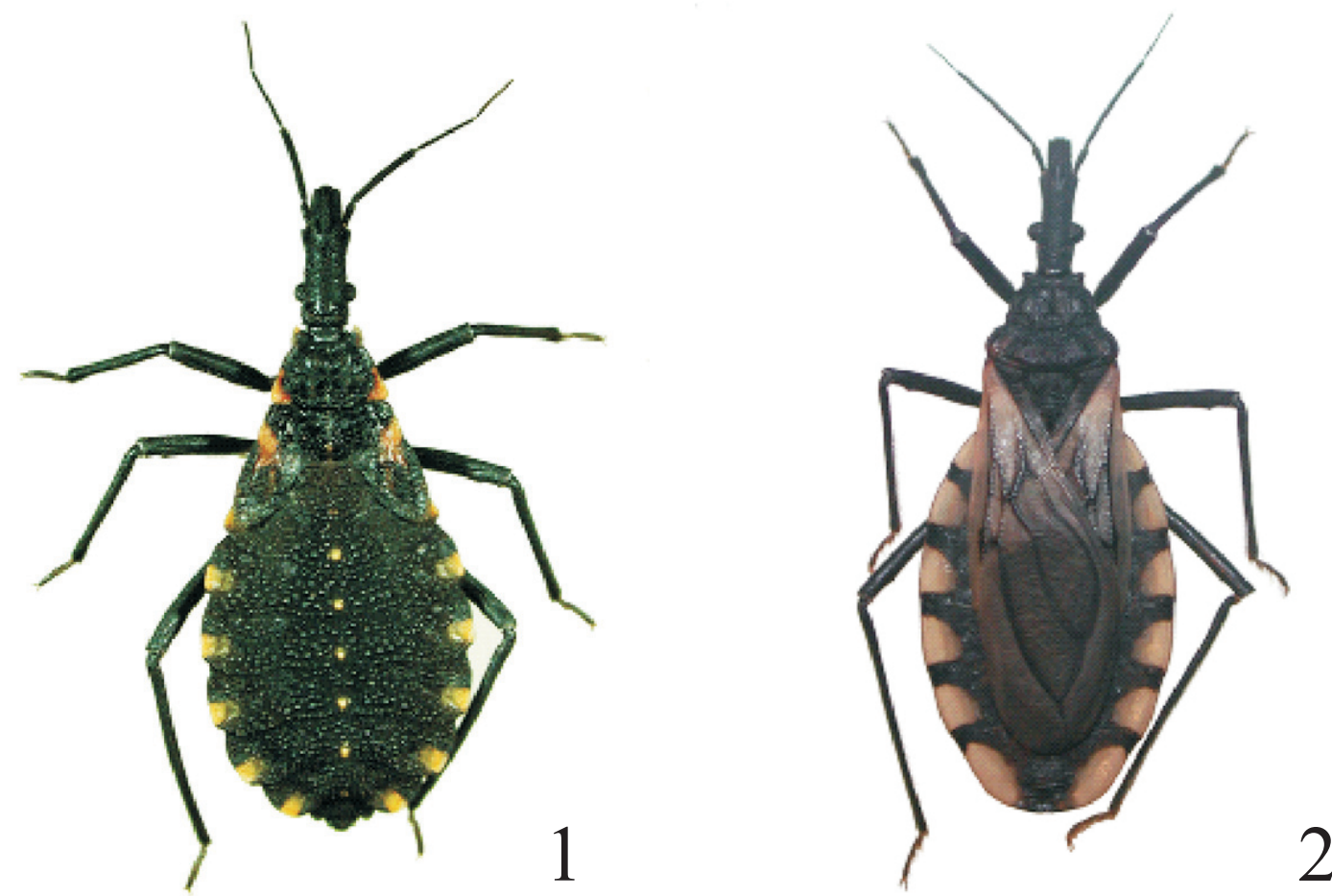

Figuras 1, 2. Triatoma klugi Carcavallo, Jurberg, Lent \& Galvão, 2001: 1, ninfa de $5^{\circ}$ estádio; 2, macho adulto. 
recém-eclodidas. Após a observação dos aspectos cromáticos, as ninfas foram montadas em lâminas e coladas em posição padrão, sendo posteriormente desenhadas a seco com o auxílio de uma câmara clara acoplada a um microscópio estereoscópico. Os ovos fragmentados foram montados entre lâmina e lamínula com álcool, desenhados em microscópio biológico.

Microscopia eletrônica de varredura. Para análise ultra-estrutural, três ovos após a postura foram selecionados e três ninfas de cada estádio foram escolhidas após a eclosão e ecdises. Os insetos foram mortos por congelamento e desidratados em incubadora a $37^{\circ} \mathrm{C}$ for $24 \mathrm{~h}$. A seguir, o material foi fixado com fita dupla face em suportes metálicos com 1,2 cm de diâmetro, metalizado com ouro e analisado em microscópio eletrônico de varredura. As imagens foram capturadas digitalmente e processadas no programa Adobe Photo Shop 6.0.

Mensuração de ovos e ninfas. Foram utilizadas três ninfas de cada estádio e três ovos. O material foi analisado em microscópio estereoscópico, com auxílio de uma ocular graduada aferida com uma lâmina micrométrica de um milímetro dividida em 100 partes.

\section{RESULTADOS}

O ovo de cor esbranquiçada apresenta comprimento em média de 2,04 mm (Fig. 3) e a largura máxima de $1,36 \mathrm{~mm}$ tendo como proporção entre o comprimento e a largura 1:0,66. A análise por microscopias óptica e eletrônica de varredura mostra que a superfície dos ovos apresenta células na sua maioria pentagonais, e também poligonais e hexagonais, sendo que as células do opérculo são menores que as do corpo e ornamentadas por sulcos microscópicos e as células do corpo por pontuações, em ambas com distribuição aleatória (Figs. 4-7).

Ninfas, primeiro estádio (Fig. 8). Comprimento total 4,7 +/- 0,09 mm. Coloração parda, apresentando na cabeça cerdas longas inseridas em tubérculos setíferos dispostos aleatoriamente do clípeo à calosidade pós-ocular. Os três segmentos torácicos encontram-se lateralmente ornamentados por uma faixa um pouco mais clara, contendo cerdas dispostas aleatoriamente, inclusive nos bordos laterais. No pronoto observam-se $1+1$ áreas glabras centrais. No abdome, os urotergitos apresentamse com 1+1 fileiras paralelas de cerdas, inseridas em tubérculos setíferos e ainda, 1+1 placas retangulares dispostas lateralmente no nono urotergito.

Cabeça de coloração parda, em vista dorsal, devido à presença de tubérculos setíferos distribuídos aleatoriamente por toda sua extensão, o que lhes confere um tegumento de aspecto irregular. Calosidades pósoculares presentes. A cabeça apresenta, entre as regiões pós-ocular e a anteocular, a proporção média de 1:1,5 e entre a largura nas regiões inter-ocular e ocular, a proporção média de 1:1,7 (Tab. I).

Olhos compostos de coloração negra, constituídos por omatídeos circulares justapostos, aumentando em número e diminuindo o espaço entre eles nos demais estádios. Apresentam uma área póstero-inferior lisa e sem omatídeos.

Antenas tetrarticuladas, inseridas em tubérculos anteníferos implantadas lateralmente no limite do terço anterior da cabeça. Estes tubérculos apresentam lateralmente, uma protuberância com uma única cerda

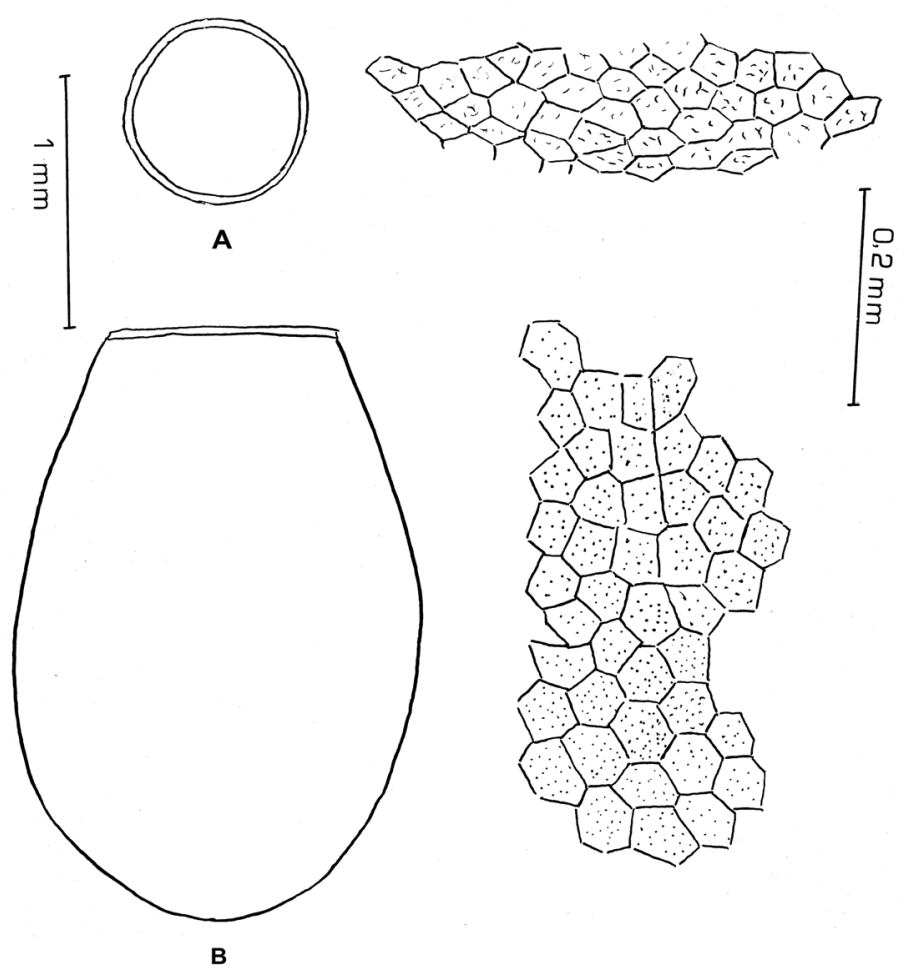

Figura 3. Ovo de Triatoma klugi Carcavallo, Jurberg, Lent \& Galvão, 2001, visto por meio de microscopia óptica (A, opérculo com detalhe dos sulcos; B, corpo do ovo com detalhe do exocório e das perfurações). 
implantada em seus ápices. Artículos antenais apresentam as seguintes proporções médias 1:1,7:2,6:2,8 (Tab. I)

Rostro triarticulado, retilíneo com o $3^{\circ}$ segmento atingindo o bordo anterior do proesterno quando em repouso. Apresenta coloração, um pouco mais clara que a cabeça. Os três segmentos encontram-se ornamentados por sensilas que aumentam em quantidade e tamanho no $3^{\circ}$ segmento. Os três segmentos apresentam as seguintes proporções médias 1:2,4:1,2 (Tab. I)

Tórax de coloração mais escura do que a cabeça, ornamentado dorsalmente por cerdas implantadas em tubérculos distribuídos aleatoriamente, inclusive nos bordos laterais.

Pronoto trapezoidal, ornamentado dorsalmente por uma faixa clara mais evidente nos bordos inferiores, contendo cerdas implantadas em tubérculos setíferos aleatoriamente dispostos. Ângulos discais presentes.
Mesonoto formado por 1+1 placas retangulares de bordos internos retos, lateralmente ornamentados por uma faixa mais clara, contendo cerdas esparsas.

Metanoto de mesma coloração que os outros segmentos, formado por $1+1$ placas com bordos internos arredondados, ornamentados por cerdas esparsas.

Pernas castanho-escuras em sua totalidade, ornamentadas por fileiras duplas e paralelas nos fêmures e tíbias. Coxa globosa e menos pilosa que os outros segmentos. Tarsos com maior número de cerdas.

Abdome de coloração um pouco mais clara que o tórax e a cabeça, forma ovalada, com nove segmentos visíveis bem demarcados, face dorsal plana e ventral convexa. Os tergitos são dorsalmente ornamentados por cerdas dispostas por $1+1$ fileiras paralelas. No nono segmento constam $1+1$ placas retangulares ocupando o bordo superior.
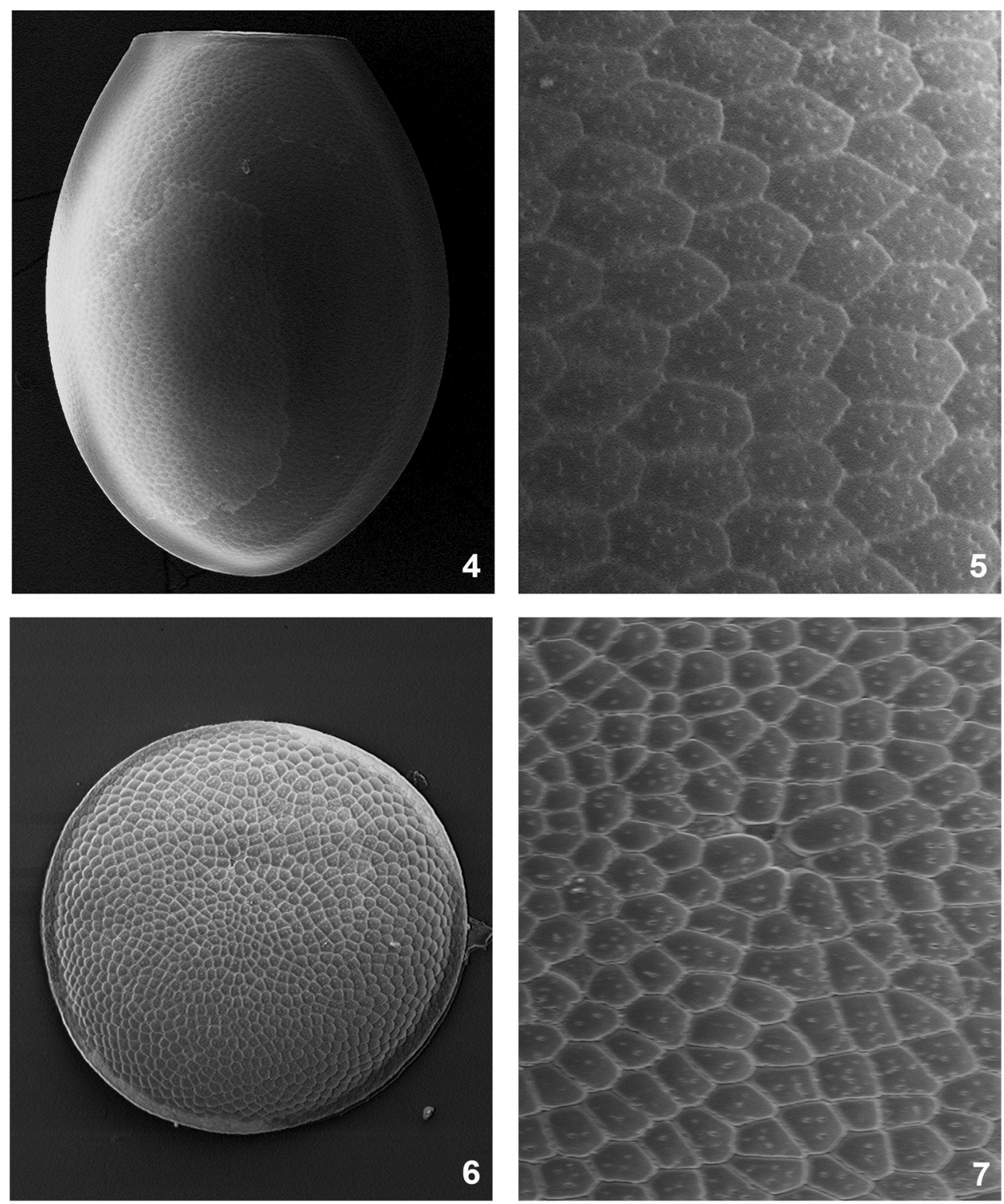

Figuras 4-7. Ovo de Triatoma klugi Carcavallo, Jurberg, Lent \& Galvão, 2001, visto por meio de microscopia eletrônica de varredura; 4, corpo do ovo (133X); 5, detalhe dos polígonos do corpo (1000X); 6, opérculo (200X); 7, detalhe dos polígonos do opérculo (1000X). 
Ninfas, segundo estádio (Fig. 9). Comprimento total 6,2 +/- 0,02 mm. Coloração parda. Cabeça com cerdas implantadas em tubérculos setíferos com maior concentração nas genas e na fronte, o que lhe confere um aspecto granuloso. Apresenta, entre as regiões pósocular e a anteocular, a proporção média de 1:2,0 e, entre a largura das regiões interocular e ocular, a proporção média de 1:1,5 (Tab. I).

Tórax de coloração negra. Os três segmentos são contornados lateralmente por faixas claras limitantes, sendo que, no protórax, elas estão presentes nos ângulos humerais e nos bordos inferiores, ornamentados por cerdas implantadas em tubérculos esparsadamente. Abdome de coloração parda, manchas conexivais visíveis a partir do $2^{\circ}$ segmento, ornamentados por fileiras de cerdas dispostas paralelamente, $1+1$ áreas glabras centrais localizadas no bordo inferior do $2^{\circ}$ ao $5^{\circ}$ segmento, $1+1$ placas retangulares nos bordos superiores laterais do $9^{\circ}$ tergito. Pernas com coxas e trocânteres mais claros.

Artículos antenais apresentam as seguintes proporções médias 1;2,3;2,8:3,0 (Tab. I).

Os três segmentos do rostro apresentam as seguintes proporções médias 1:2,9:1 (Tab. I).
Ninfas, terceiro estádio (Fig. 10). Comprimento total 8,9 +/- 0,21 mm. Coloração parda. Apresentam cerdas implantadas em tubérculos setíferos nas genas, clípeo, fronte e vértex.

Tórax apresenta coloração negra, contendo uma faixa clara ornamentando os ângulos humerais e os bordos inferiores do pronoto, enquanto no mesotórax e metanoto, apenas nos bordos inferiores, com cerdas esparsas nos três segmentos.

Apresentam entre as regiões pós-ocular e anteocular a proporção média de 1:2,2 e entre a largura das regiões inter-ocular e ocular a proporção média de 1:1,7 (Tab. I).

Antenas com os três primeiros segmentos e a metade basal do $4^{\circ}$ segmento de coloração negra, contendo inúmeras sensilas no $2^{\circ}$ e $3^{\circ}$ segmento e o $4^{\circ}$ segmento com sensilas longas e esparsas na sua metade apical. Os artículos antenais apresentam as seguintes proporções médias 1:2,2:2,9:3,0 (Tab. I).

Abdome de coloração parda, com manchas conexivais a partir do $2^{\circ}$ segmento, ornamentado com cerdas inseridas em tubérculos setíferos dispostos em fileiras paralelas. Apresentam 1+1 áreas glabras centrais

Tabela I. Proporções médias de alguns parâmetros da cabeça de Triatoma klugi Carcavallo, Jurberg, Lent \& Galvão, 2001 (medidas em $\mathrm{mm})$.

\begin{tabular}{lccccc}
\hline Caracteres & $1^{\circ}$ estádio & $2^{\circ}$ estádio & $3^{\circ}$ estádio & $4^{\circ}$ estádio & $5^{\circ}$ estádio \\
\hline Região pós-ocular/ ante-ocular & $1: 1,5$ & $1: 2,0$ & $1: 2,2$ & $1: 2,6$ & $1: 2,4$ \\
Largura das regiões Inter-ocular/ocular & $1: 1,7$ & $1: 1,5$ & $1: 1,7$ & $1: 1,7$ & $1: 1,6$ \\
Segmentos antenais & $1: 1,7: 2,6: 2,8$ & $1: 2,3: 2,8: 3,0$ & $1: 2,2: 2,9: 3,0$ & $1: 2,5: 2,4: 2,7$ & $1: 3,3: 2,7: 2,5$ \\
Segmentos do rostro & $1: 2,4: 1,2$ & $1: 2,9: 1,2$ & $1: 2,5: 1,3$ & $1: 2,4: 1,2$ & $1: 1,8: 0,9$ \\
\hline
\end{tabular}

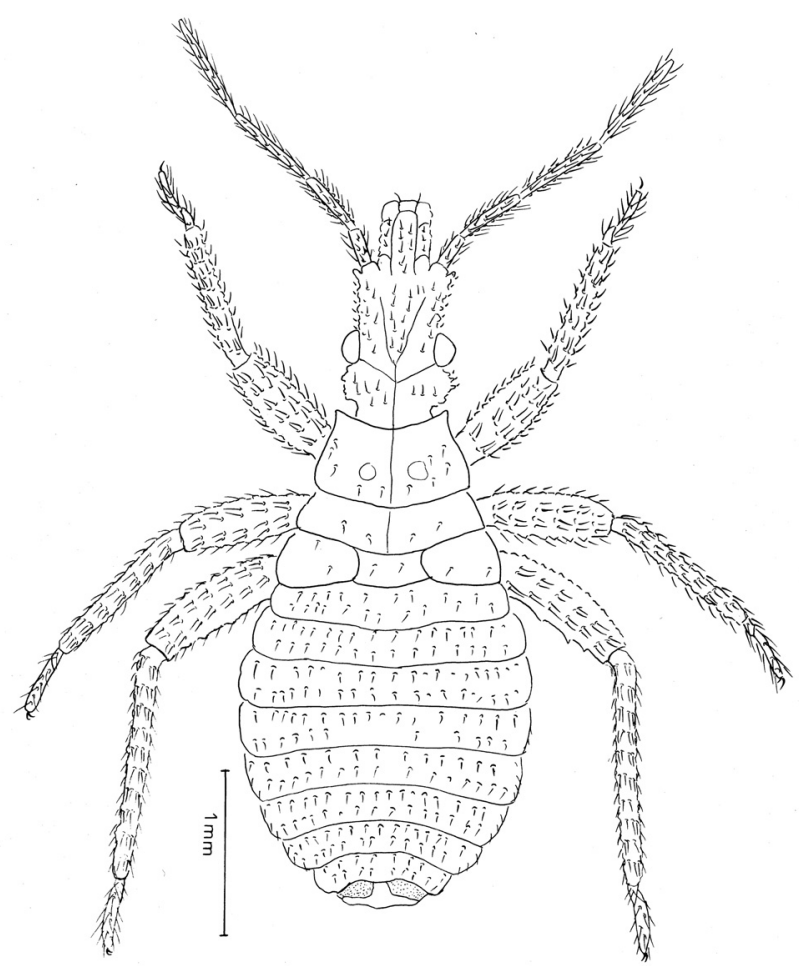

Figura 8. Triatoma klugi Carcavallo, Jurberg, Lent \& Galvão, 2001, ninfa de $1^{\circ}$ estádio, vista dorsal.

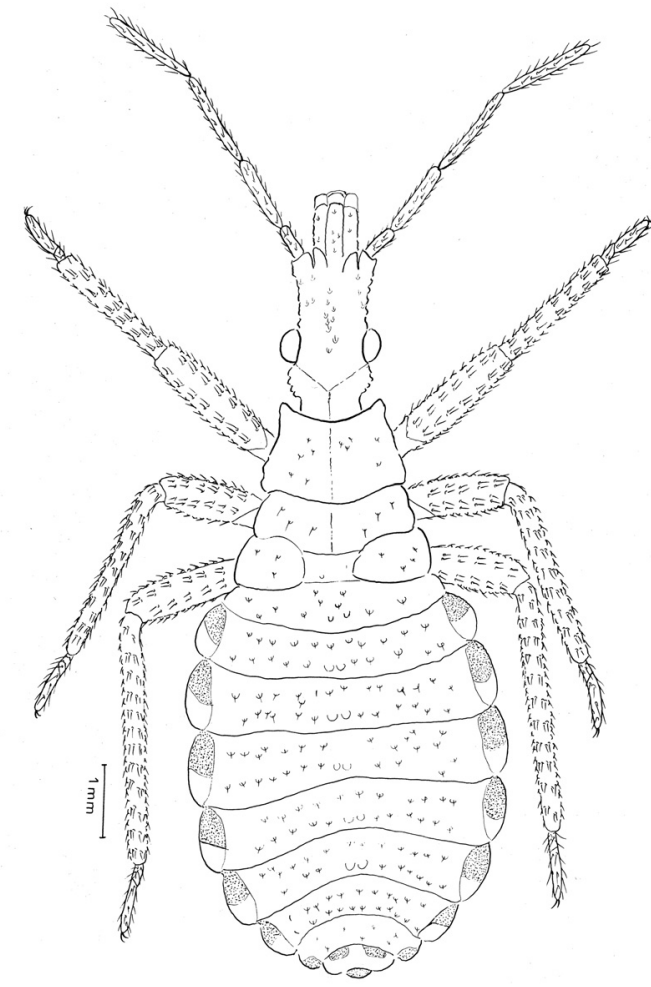

Figura 9. Triatoma klugi Carcavallo, Jurberg, Lent \& Galvão, 2001, ninfa de $2^{\circ}$ estádio, vista dorsal. 
no bordo inferior do $2^{\circ}$ ao $6^{\circ}$ tergito e $1+1$ placas localizadas na porção média do bordo superior do $9^{\circ}$ tergito. O conexivo apresenta zonas ovaladas mais escuras em sua metade superior. Pernas de coloração negra, contendo fileiras paralelas de cerdas nas faces externas dos fêmures e das tíbias.

Os três segmentos do rostro apresentam as seguintes proporções médias 1:2,5:1,3 (Tab. I).

Ninfas, quarto estádio (Fig. 11). Comprimento total 12,1 +/- 0,58 mm. Coloração castanho parda. Cabeça com aumento no número de cerdas implantadas em tubérculos, conferindo-lhe um aspecto granuloso. As tecas alares encontram-se evidenciadas. Apresenta entre as regiões pós-ocular e ante-ocular a proporção média de 1:2,6 e entre a largura nas regiões inter-ocular e ocular a proporção média de 1:1,7 (Tab. I).

Tórax negro, o pronoto apresenta regiões claras nos ângulos humerais e no mesonoto, nos bordos superiores e inferiores e no metanoto, apenas nos bordos inferiores.

Abdome contendo o maior número de cerdas implantadas em tubérculos de forma aleatória, contendo uma área glabra central no bordo inferior do $2^{\circ}$ ao $6^{\circ}$ tergito.

Pernas negras e longas, contendo nos fêmures e tíbias cerdas dispostas em fileiras duplas e paralelas.

Artículos antenais apresentam as seguintes proporções médias 1:2,5:2,4:2,7 (Tab. I).

Os três segmentos do rostro apresentam as seguintes proporções médias 1:2,4:1,2 (Tab. I).

Ninfas, quinto estádio (Fig. 12). Comprimento total

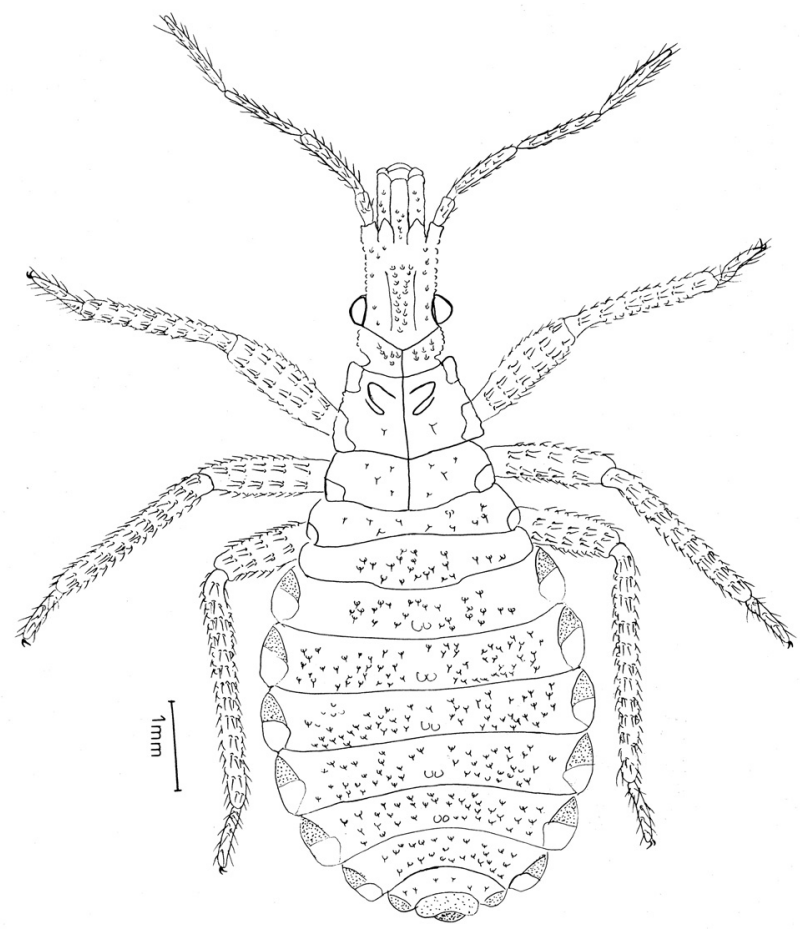

Figura 10. Triatoma klugi Carcavallo, Jurberg, Lent \& Galvão, 2001, ninfa de $3^{\circ}$ estádio, vista dorsal.
17,7 +/- 0,58 mm. Cabeça de coloração negra, clípeo unilobado, jugas de formato triangular, aumento do número de cerdas por toda sua extensão conferindo-lhe um aspecto granuloso, diminuindo no pescoço, $1+1$ protuberâncias dorsais no ponto de surgimento dos ocelos. Olhos compostos negros, constituídos por omatídeos justapostos. As antenas apresentam os três primeiros segmentos e a base do quarto de coloração negra. Apresentam entre as regiões pós-ocular e anteocular a proporção média de 1:2,4 e entre a largura das regiões inter-ocular e ocular a proporção média de 1:1,6 (Tab. I).

Tórax negro, apresentando as tecas alares mais pilosas e se estendem até o final do $2^{\circ}$ segmento abdominal. Contém faixas claras nos ângulos humerais e no bordo inferior do protórax e uma área glabra central no bordo inferior do mesotórax. Abdome mostra manchas conexivais com zonas ovaladas mais escuras na parte superior, uma área glabra no bordo inferior central do $2^{\circ}$ ao $6^{\circ}$ segmento. Pernas negras ornamentadas por duas fileiras de cerdas paralelas nas tíbias e fêmures dos três pares.

Artículos antenais apresentam a seguintes proporções médias 1:3,3:2,7:2,5 (Tab. I).

Os três segmentos do rostro apresentam as seguintes proporções médias 1:1,8:0,9 (Tab. I).

Por meio de análise ultra-estrutural das ninfas podese observar as alterações morfológicas durante o desenvolvimento ninfal da face ventral da cabeça e dos últimos segmentos abdominais (IX, X e XI - tubo anal, futura genitália).

Na região interocular ventral, observa-se nas ninfas de primeiro estádio uma diferenciação do tecido reticular

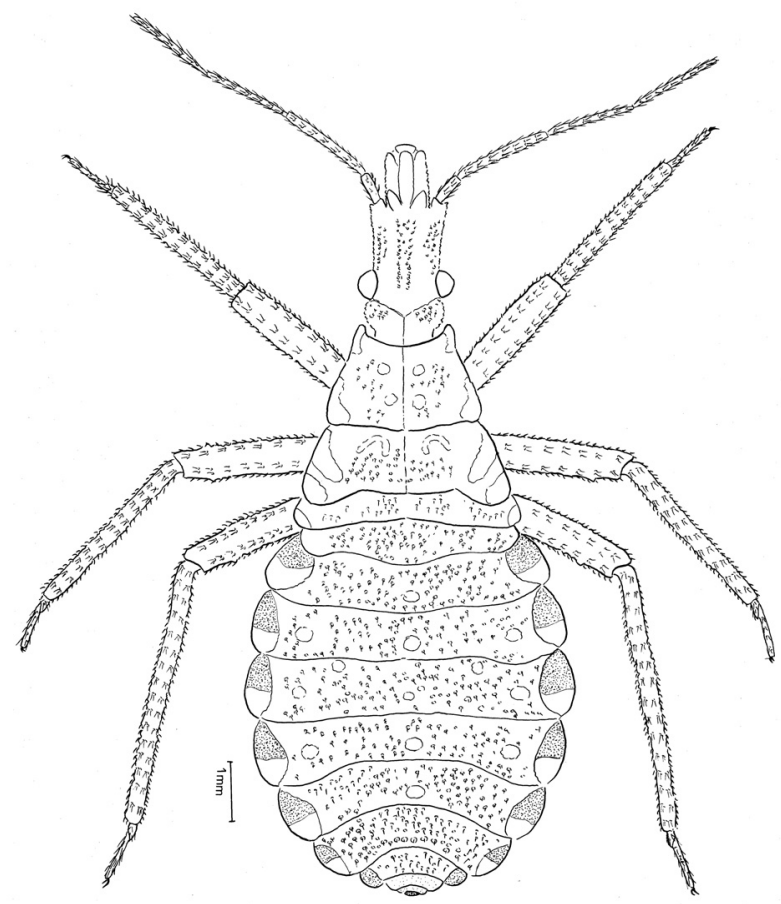

Figura 11. Triatoma klugi Carcavallo, Jurberg, Lent \& Galvão, 2001, ninfa de $4^{\circ}$ estádio, vista dorsal. 
logo abaixo dos olhos compostos e algumas papilas (Fig. 13). No terceiro estádio, nota-se um aumento de tubérculos arredondados, o tecido reticular fica mais uniforme, constando 1+1 áreas glabras de formato ovalar (Fig. 14). No quinto estádio, essas áreas de formato ovalar apresentam a extremidade anterior afilada e a posterior arredondada, circundadas por papilas, sendo que no bordo interno, estas se limitam ao contorno da área lisa e glabra. Em torno dessa estrutura, visualizam-se algumas cerdas distribuídas aleatoriamente, podendo tratar-se de algumas cerdas que se modificam com evolução dos estádios (Fig. 15). O sulco estridulatório localizado no pré-externo apresenta-se no primeiro estádio como uma área ovalada, cuja superfície está repleta de elevações paralelas, limitadas lateralmente por tubérculos sem cerdas (Figs. 16, 17). No segundo estádio a área se transforma numa região triangular que atinge o bordo superior da cavidade coxal do primeiro par de pernas, limitada lateralmente em ambos os lados por tubérculos setíferos com pelos decumbentes (Figs. 16-19). Nas ninfas de terceiro estádio as características morfológicas do sulco estridulatório são semelhantes (Figs. 20, 21).

Visto lateralmente, com o rostro distendido, a búcula se apresenta como uma placa retangular menos quitinizada, sendo que, no primeiro estádio, com poucos tubérculos (Fig. 22). No terceiro estádio a búcula apresenta um número maior de tubérculos e 1+1 carenas logitudinais levemente elevadas (Fig. 23) e no quinto estádio com as carenas fortemente elevadas (Fig. 24).

A análise ultra-estrutural dos últimos segmentos abdominais se caracteriza por apresentar o X segmento (tubo anal) de forma anelar, ornamentado por tegumento enrugado mostrando parcialmente no seu

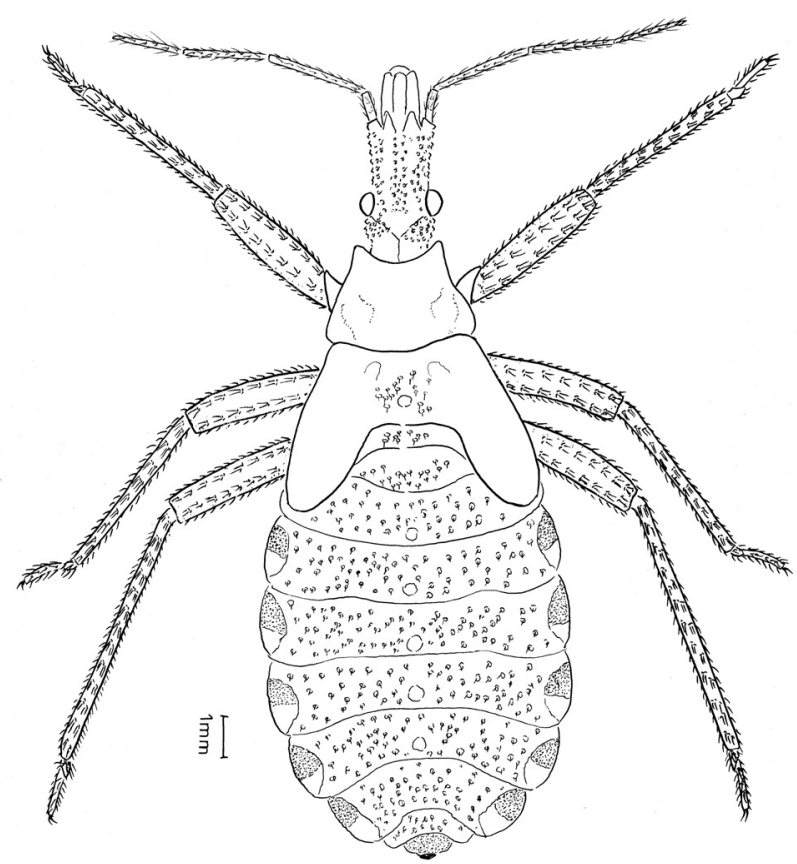

Figura 12. Triatoma klugi Carcavallo, Jurberg, Lent \& Galvão, 2001, ninfa de $5^{\circ}$ estádio, vista dorsal. interior o ânus que fica telescopado e se caracteriza por apresentar 1 placa dorsal +1 placa ventral com os bordos externos ornamentados com cerdas finas e longas (Figs. 25, 26).
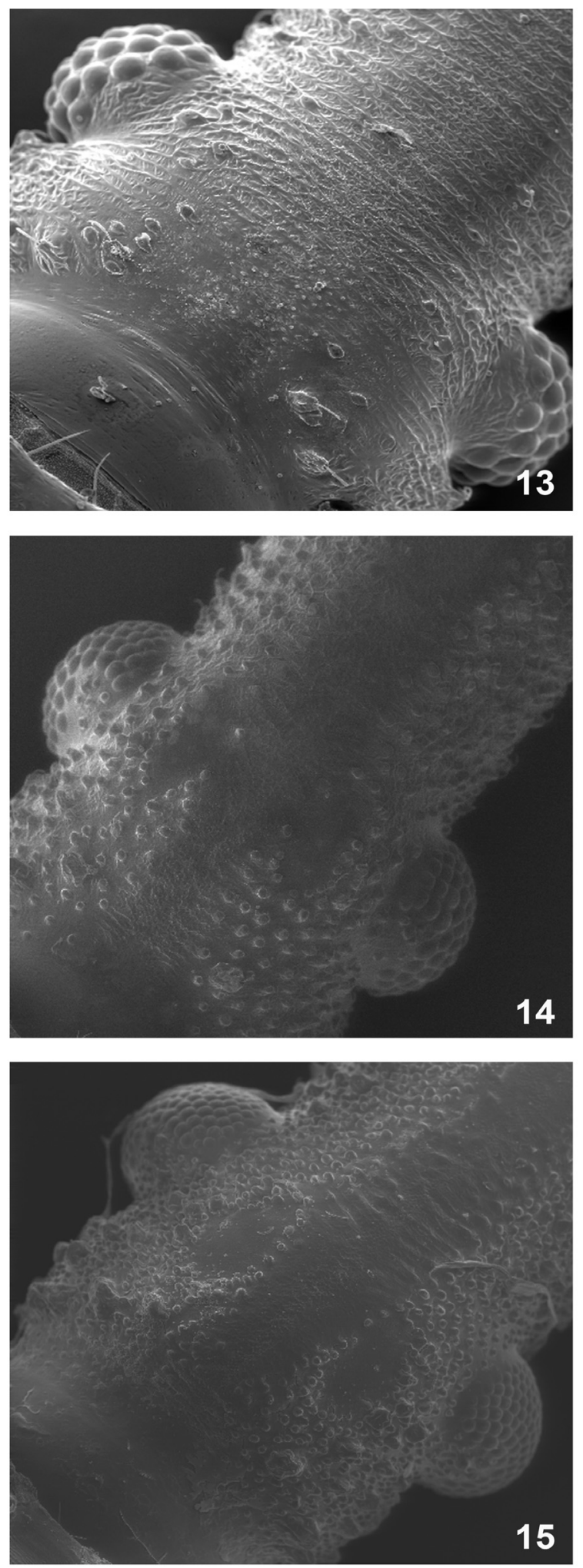

Figuras 13-15. Triatoma klugi Carcavallo, Jurberg, Lent \& Galvão, 2001 , vista ventral da região inter-ocular; 13 , ninfa de $1^{\circ}$ estádio $(165 \mathrm{X}) ; 14$, ninfa de $3^{\circ}$ estádio $(80 \mathrm{X}) ; 15$, ninfa de $5^{\circ}$ estádio $(50 \mathrm{X})$. 

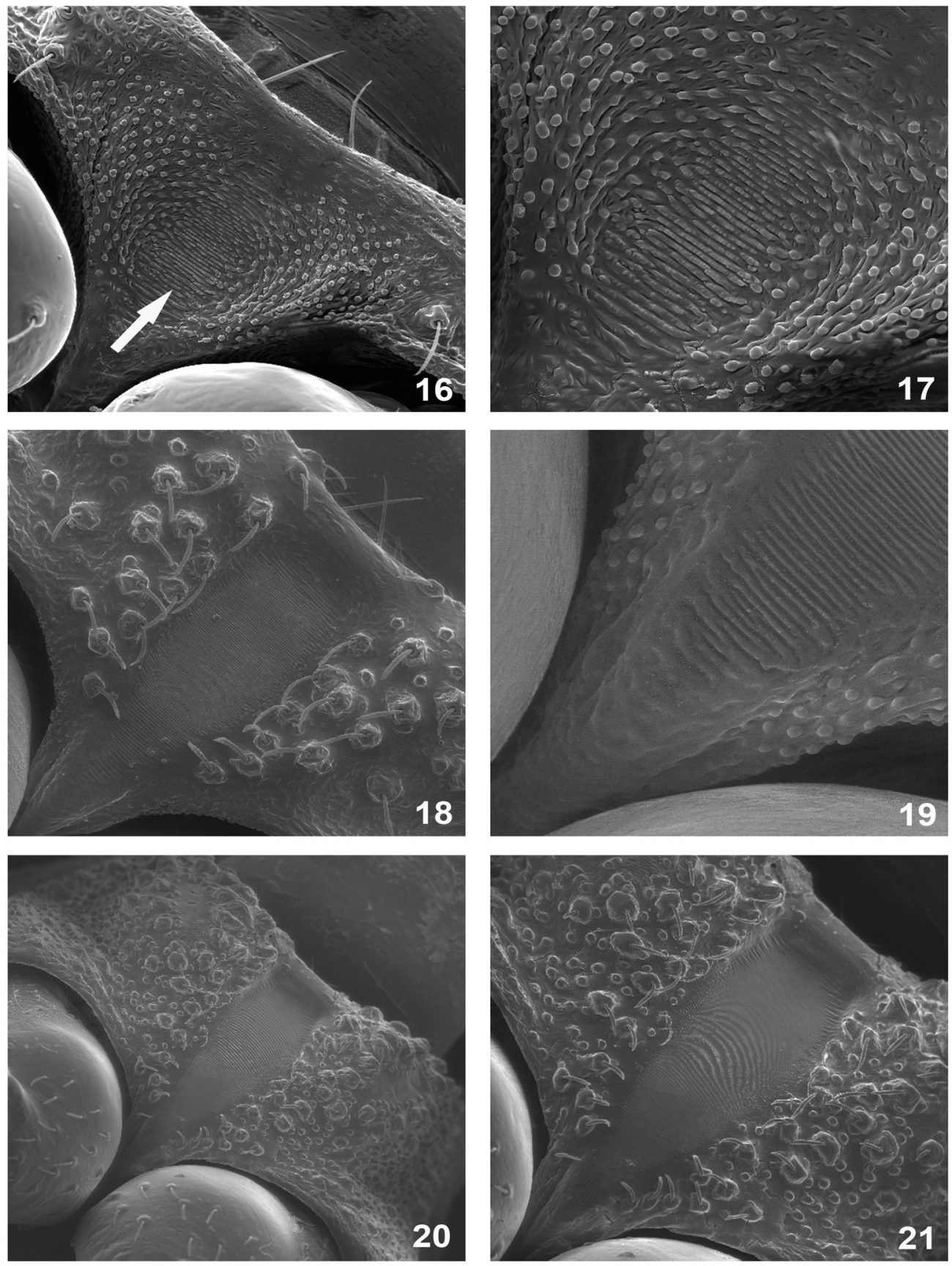

Figuras 16-21. Triatoma klugi Carcavallo, Jurberg, Lent \& Galvão, 2001, vista ventral do sulco estridultório: 16 , ninfa de $1^{\circ}$ estádio (200X); 17 , ninfa de $1^{\circ}$ estádio (380X); 18, ninfa de $3^{\circ}$ estádio (200X); 19 , ninfa de $3^{\circ}$ estádio (380X); 20 , ninfa de $5^{\circ}$ estádio (160X); 21 , ninfa de $5^{\circ}$ estádio (300X).

\section{DISCUSSÃO}

A análise de ovos e três estádios ninfais de T. klugi por meio de microscopia eletrônica de varredura mostrou diferenças morfológicas na face ventral e dorsal da cabeça e nos últimos segmentos abdominais (IX, X e XI - tubo anal, futura genitália), no sulco estridulatório, búcula, rostro e antenas durante o desenvolvimento das ninfas, constituindo, assim, novos parâmetros para identificação de espécies afins.

Na década de oitenta, alguns autores preocuparamse com as características dos ovos ao estudar as espécies, fornecendo detalhes macroscópicos como: tamanho, forma, coloração, tipo de casca, fixação, entre outros (BARATA, 1984). Utilizando a microscopia óptica e a microscopia eletrônica de varredura, BARATA (1984) mostrou a possibilidade de empregar as estruturas e as distintas ornamentações dos ovos como parâmetros na diagnose das espécies, elaborando uma chave para a identificação de dez espécies do gênero Rhodnius. Aspectos da morfologia externa e do exocório e as dimensões dos ovos em nove dos quinze gêneros conhecidos de Triatominae foram descritos por BARATA (1998). 

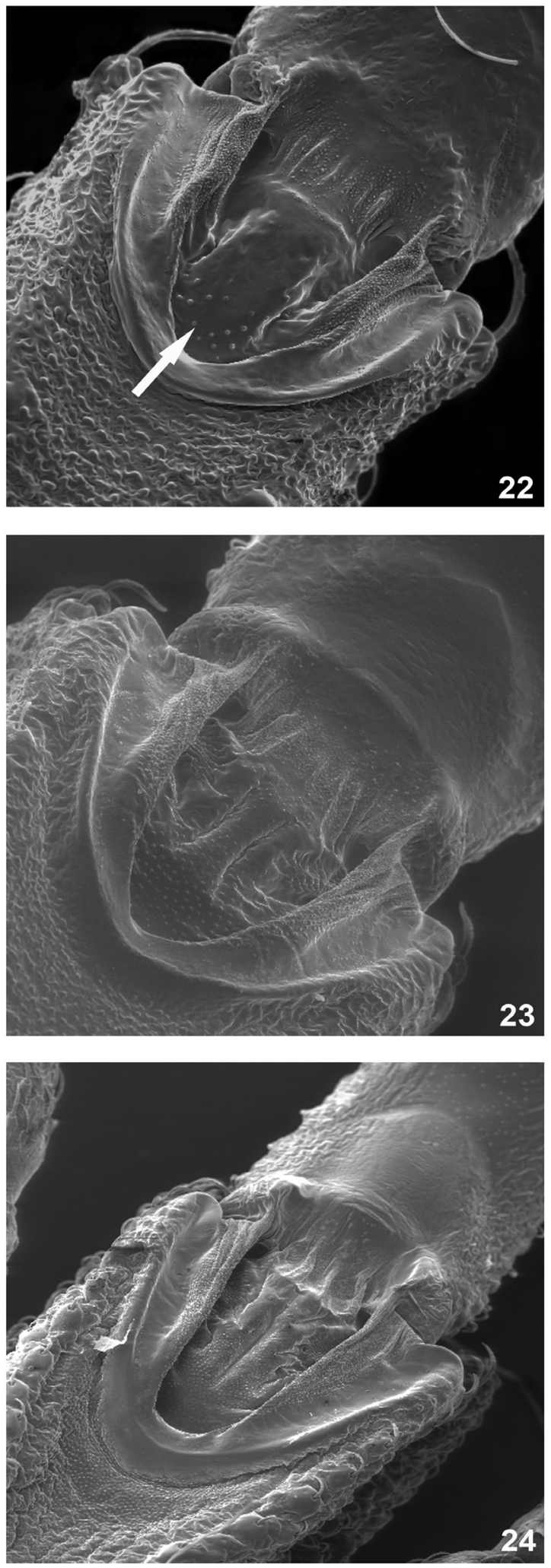

Figuras 22-24. Triatoma klugi Carcavallo, Jurberg, Lent \& Galvão, 2001, vista lateral da búcula, com o rostro distendido: 22, ninfa de $1^{\circ}$ estádio (310X); 23, ninfa de $3^{\circ}$ estádio (200X); 24, ninfa de $5^{\circ}$ estádio $(88 \mathrm{X})$.

A superfície do exocório dos ovos de T. klugi apresenta as células do opérculo ornamentadas por traços aleatórios e as do corpo, por pontuações com a mesma distribuição, enquanto a espécie afim, T. williami, apresenta as células ornamentadas por pontuações dispostas ao acaso no corpo e no opérculo (SILVA et al., 2005). Comparativamente, esses ovos quando foram observados por microscopia óptica apresentaram características macroscópicas no seu exocório capazes de distinguir as espécies pertencentes ao mesmo complexo. Em T. matogrossensis, o exocório é formado por um sistema de linhas irregulares e curvadas que se comunicam entre si, podendo em alguns polígonos, formar figuras fechadas (JuRBERG \& Vogel, 1994). Em T. guazu, o opérculo e o corpo são formados por células ornamentadas por pequenas perfurações distribuídas ao acaso (SiLva et al., 2000), enquanto T. jurbergi apresenta o opérculo ornamentado por pequenas fraturas e o corpo, além de pequenas fraturas, pontuações distribuídas ao acaso (SILVA et al., 2000).

Atualmente, ainda não existe uma chave geral que relacione taxonomicamente os cinco estádios ninfais das espécies, apesar de existirem numerosos trabalhos sobre morfologia das ninfas de várias espécies de triatomíneos (Lent \& Wygodzinsky, 1979; CARCAVAllo et al., 1997; SiLVA et al., 2000, 2005). LeNT \& WygodZINSKy (1979) conseguiram agrupar as espécies com base nos caracteres das ninfas, conseguindo elaborar uma chave para o primeiro e o quinto estádios ninfais, que permitiu identificar os gêneros de triatomíneos utilizando a estrutura dorsal do abdome.

No presente trabalho pode-se constatar, dentre outras diferenças, as relacionadas às manchas conexivais que surgem a partir do segundo estádio. Em T. klugi, estas manchas são bem definidas, ocupando a metade superior do segmento, enquanto em T. williami, estas manchas conexivais são pouco definidas, ocupando uma parte da porção superior dos segmentos abdominais. No entanto, também se podem observar diferenças cromáticas entre essas espécies. Essa característica que diferencia as espécies estudadas, também foi observada em todos os estádios das ninfas de T. matogrossensis, T. guazu, T. vandae Carcavallo, Jurberg, Rocha, Galvão, Noireau \& Lent, 2002 e T. williami do "complexo oliveirai" (JURBERG \& Vogel, 1994; SiLva et al., 2000; JuRberg et al., 2002).

Por meio de microscopia eletrônica de varredura tem sido possível realizar estudos taxonômicos na entomologia, auxiliando nas investigações e nas análises das estruturas (CARCAVAllo et al., 1994a, 1997). Esses estudos têm permitido também a distinção entre as espécies afins, crípticas e entre os complexos específicos. Diversos autores têm buscado novos parâmetros que, associados aos apresentados por LENT \& WYGODZINSKY (1979), permitam avançar e tentar elaborar uma chave de identificação específica.

SILVA et al. (2005) realizaram uma análise ultraestrutural dos aspectos gerais dos últimos segmentos abdominais de T. williami, onde evidenciaram alterações morfológicas durante o desenvolvimento ninfal dessa espécie. Realizamos uma análise comparativa dos últimos segmentos abdominais do primeiro, terceiro e quinto estádios entre as duas espécies. Com relação ao $\mathrm{X}$ segmento abdominal das ninfas de primeiro estádio, observamos que T. klugi apresentou algumas cerdas e que T. williami apresentou cerdas por toda circunferência abdominal. Em T. williami, pode-se visualizar no IX 

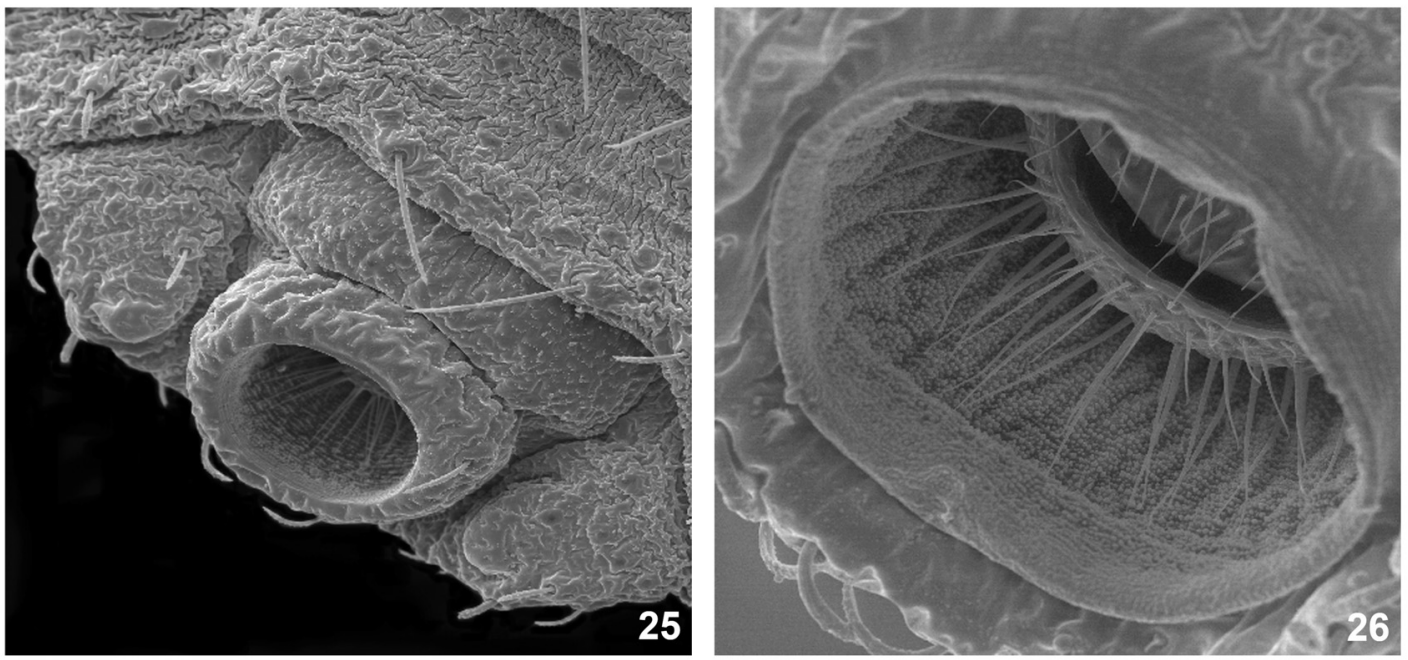

Figuras 25, 26. Triatoma klugi Carcavallo, Jurberg, Lent \& Galvão, 2001, vista ventral dos últimos segmentos abdominais: 25, ninfa de $2^{\circ}$ estádio (100X); 26 , ninfa de $2^{\circ}$ estádio (380X).

segmento, tubérculos setíferos proeminentes com cerdas de ápice rombo e serrilhado. Essa característica não foi observada em T. klugi. A morfologia dos últimos segmentos abdominais das ninfas dos triatomíneos foi evidenciada por vários autores (EsPínOLA, 1966; JURBERG et al., 1970; DA Rosa et al., 1992a, b) que abordaram a definição do futuro sexo através de sua configuração.

CARCAVAllo et al. (1994a, c, 1995) evidenciaram semelhanças e diferenças com valor sistemático da região óculo-ocelar das espécies conhecidas do gênero Rhodnius, de onze espécies do gênero Panstrongylus Berg, 1879 e do gênero Psammolestes Bergroth, 1911. Nos dados aqui descritos, pode-se observar que a configuração dessas estruturas varia com a evolução dos estádios em T. klugi como também em T. williami.

Assim, este trabalho contribui com uma análise detalhada de algumas áreas da anatomia externa dos triatomíneos em continuidade à descrição de outras espécies afins e crípticas (CARCAVAllo et al., 1998; SiLVA et al., 1999, 2000, 2002, 2003; JURBERG et al., 2002) visando o esclarecimento do status dessas espécies.

Agradecimentos. Ao Conselho Nacional de Pesquisa e Desenvolvimento Tecnológico $(\mathrm{CNPq})$ e à Secretaria de Vigilância em Saúde (SVS) do Ministério da Saúde, pelo apoio financeiro.

\section{REFERÊNCIAS}

Abalos, J. W. \& Wygodzinsky, P. 1951. Las Triatominae Argentinas (Reduviidae, Hemiptera). Anales del Instituto Médico Regional Tucumán, 2, 1:179.

Barata, J. M. S. 1981. Aspectos morfológicos de ovos de Triatomíneos. II - Características macroscópicas e exocoriais de dez espécies do gênero Rhodnius Stål, 1859 (HemipteraReduviidae). Revista de Saúde Pública de São Paulo 15:490-542.

1998. Macroscopic and exocorial structures of Triatominae eggs (Hemiptera, Reduviidae). In: Carcavallo, R. U.; GalíndeZ Girón, I.; Jurberg, J. \& Lent, H. eds. Atlas dos Vetores da doença de Chagas nas Américas. Rio de Janeiro, Fiocruz. v.2, p.409-448.

BARTH, R. \& Muth, H. 1958. Estudos anatômicos e histológicos sobre a Subfamília Triatominae (Heteroptera, Reduviidae). VIII parte: Observações sobre a superfície de ovos de espécies mais importantes. Memórias do Instituto Oswaldo Cruz 56:197-208

Brener, Z. \& Andrade, Z. 1979. Trypanosoma cruzi e doença de Chagas. Rio de Janeiro, Ed. Guanabara Koogan S.A. $463 p$.

Carcavallo, R. U.; Galíndez-Gíron, I.; Jurberg, J. \& Martínez, A 1994a. La región óculo-ocelar en el género Panstrongylus Berg, 1879 (Hemiptera, Reduviidae, Triatominae). Entomología y Vectores 1:113-120.

Carcavallo, R. U.; Galíndez-Gíron, I.; Martínez, A. \& Jurberg, J. 1994b. Cuticular structures of Triatominae. Their taxonomic significance. Entomología y Vectores 1:79-91.

Carcavallo, R. U.; Jurberg, J.; Martínez, A. \& Galíndez-Gíron, I. 1994c. La región óculo-ocelar en género Rhodnius Stål, 1859 (Hemiptera, Reduviidae, Triatominae). Entomología y Vectores 1:21-32.

Carcavallo, R. U.; Galíndez-Gíron, I. \& Jurberg, J. 1995. La región óculo-ocelar en el género Psammolestes Bergroth, 1911 (Hemiptera, Reduviidae, Triatominae). Entomología y Vectores 2:113-116.

Carcavallo, R. U.; Galíndez-Girón, I.; Catalá, S.; Jurberg, J.; Lent, H.; Galvão, C.; Barata, J. M. S. \& Valderrama, A. 1997. Some anatomic structures studied with canning electron microscopy (SEM). In: Carcavallo, R. U.; Galíndez Girón, I.; Jurberg, J. \& Lent, H. eds. Atlas dos Vetores da doença de Chagas nas Américas. Rio de Janeiro, FIOCRUZ. v.1, p.299-393.

Carcavallo, R. U.; Jurberg, J. \& Lent, H. 1999. Filogenia dos triatomíneos. In: Carcavallo, R. U.; Galíndez Girón, I.; JuRBerg, J. \& Lent, H. eds. Atlas dos vetores da doença de Chagas nas Américas. Rio de Janeiro, FIOCRUZ. v.3, p.925-969.

Carcavallo, R. U.; Justus, N. S. \& Martinez, A. M. 1978. Descripción del las ninfas de II, III y IV estadio de Alberprosenia goyovargasi Martinéz \& Carcavallo, 1977 (Hemiptera, Reduviidae, Triatominae). Observaciones com microscopia eletrónica de barrido. Boletim de la Dirección de Malariologia e Sanidad Ambiental 18:131,132.

Carcavallo, R. U.; Otero, M. A.; Martinez, A. \& Tonn, R. J. 1975. Notas sobre la biología, ecología y distribución geográfica del Psammolestes arthuri (Pinto), 1926 (Hemiptera, Reduviidae). Descripción de los estadios preimagales. Boletim de la Dirección de Malariologia e Sanidad Ambiental 15:231-239. Carcavallo, R. U.; Rodríguez, M. E. F.; Salvatella, R.; Susana, I.; Sherlock, I. S.; Galvão, C.; Rocha, S. R.; Galídez-Giron, I.; Otero, M. A.; Arocha, O.; Martínez, A.; Da Rosa, J. A.; Canale, D. M.; FARR, T. H. \& BaRATA J. M. S. 1998. Habitats e faun relacionada. In: Carcavallo, R. U.; Galíndez Girón, I.; JuRBerG, J. \& Lent, H. eds. Atlas dos Vetores da doença de Chagas nas Américas. Rio de Janeiro, FIOCRUZ. v.2, p.561-619. 
Costa, J. M.; Jurberg, J. \& BARTh, M. O. 1991 Estudos morfológicos de Cavernicola lenti Barrett \& Árias, 1985 (Hemiptera, Reduviidae, Triatominae). Memórias do Instituto Oswaldo Cruz 86(2): 247-263.

Da Rosa, J. A.; Barata, J. M. S. \& Barelli, N. 1992a. Spiracles of $5^{\text {th }}$ Instar nynphs in six species of Triatominae (Hemiptera, Reduviidae) using scanning electron microscopy. Memórias do Instituto Oswaldo Cruz 87:301,302.

Da Rosa, J. A.; Barata, J. M. S.; Barelli, N.; Santos, J. L. F. \& Neto, F. M. B. 1992b. Sexual distinction between 5th instar nymphs of six species of Triatominae (Hemiptera, Reduviidae). Memórias do Instituto Oswaldo Cruz 87:257-264.

Espínola, H. N. 1966. Nota sobre diferenças sexuais em formas imaturas de Triatominae (Hemiptera: Reduviidae). Revista Brasileira de Biologia 26:263-267.

Galliard, H. 1935. Recherches sur les Réduvidés Hématophages Rhodnius et Triatoma. V. Morphologie de I' oeuf des Triatomes. Annales de Parasitologie Humaine et Comparée 13:511-527.

Galíndez-Girón, I.; Rocha, D. S.; Lent, H.; Carcavallo, R. U.; Jurberg, J.; Galvão, C.; Santos, H. B.; Martínez, A.; Barata, J. M. S. \& Da Rosa, J. A. 1998. Estádios Ninfais. In: Carcavallo, R. U; Galíndez Girón, I.; Jurberg, J. \& Lent, H. eds. Atlas dos vetores da doença de Chagas nas Américas. Rio de Janeiro, Editora FIOCRUZ. v.2, p.449-513.

Galvão, C.; Carcavallo, R. U.; Rocha, D. S. \& Jurberg, J. 2003. A checklist of the current valid species of the subfamily Triatominae Jeannel, 1919 (Hemiptera, Reduviidae) and their geographical distribuition, with nomenclatural and taxonomic notes. Zootaxa 202:1-36.

Gonçalves, T. C. M.; Jurberg, J.; Costa, J. M. \& Souza, W. 1985. Estudo morfológico comparativo de ovos e ninfas de Triatoma maculata (Erichson,1848) e Triatoma pseudomaculata Correa \& Espínola, 1964 (Hemiptera, Reduviidae, Triatominae). Memórias do Instituto Oswaldo Cruz 80:276-280.

Jurberg, J. \& CAMpos, P. 1995. Morfologia de huevos y ninfas de Triatoma vitticeps (Stål,1859) (Hemiptera, Reduviidae). Entomología y Vectores 2:9-22.

Jurberg, J.; Fagundes, L. M. \& Barth, O. M. 1991a. Estudo morfológico de ovos e ninfas de Dipetalogaster maximus (Uher, 1894) (Hemiptera, Reduviidae, Triatominae). Revista Brasileira de Biologia 53:269-283.

Jurberg, J.; Galvão, C. \& Barth, O. M. 1991b. Estudo morfológico de ovos e ninfas de Triatoma nitida Usinger, 1939 (Hemiptera, Reduviidae, Triatominae). Revista Brasileira de Biologia 5:365-372.

Jurberg, J. \& Galvão, C. 2006. Biology, ecology and systematics of Triatominae (Heteroptera, Reduviidae), vectors of Chagas disease, and implications for human health. Denisia 18:1-2.

Jurberg, J.; Galvão, C.; Lent, H.; Monteiro, F.; Lopes, C. M.; Panzera, F. \& Pérez, R. 1998. Revalidação de Triatoma garciabesi Carcavallo, Cichero, Martínez, Prosen \& Ronderos, 1967 (Hemiptera-Reduviidae). Entomologia y Vectores 5:107-122.

Jurberg, J.; Galvão, C.; Noireau, F.; Carcavallo, R. U.; Rocha, D. S. \& Lent, H. 2004. Uma Iconografia dos Triatomineos (Hemiptera, Reduviidae). Entomologia y Vectores 11:457-494.

Jurberg, J.; Gonçalves, T. C. M.; Costa, J. M. C. \& Souza, W. 1986. Contribuição ao estudo morfológico de ovos e ninfas de Triatoma brasiliensis Neiva, 1991 (Hemiptera, Reduviidae, Triatominae). Memórias do Instituto Oswaldo Cruz 81(1):111-120.

JuRBerg, J.; ReIs, V. R. \& Lent, H. 1970. Observações sôbre o ciclo evolutivo, em laboratório, do Rhodnius robustus Larrousse, 1927 (Hemiptera, Reduviidae, Triatominae). Revista Brasileira de Biologia 30:477-481.

Jurberg, J.; Silva, M. B. A.; Galvão, C.; Rocha, D. S.; Barbosa, H. S. \& Carcavallo, R. U. 2002. Descrição de ovos e estádios ninfais de Triatoma jurbergi Carcavallo, Galvão \& Lent, 1998 vistos através de microscopia ótica e eletrônica de varredura. (Hemiptera, Reduviidae, Triatominae). Memórias do Instituto Oswaldo Cruz 97(2):209-216.

Jurberg, J. \& Vogel, M. 1994. Morfologia de huevos y ninfas de Triatoma matogrossensis Leite \& Barbosa, 1953 (Hemiptera: Reduviidae). Entomología y Vectores 1:167-177.

Lent, H. \& Jurberg, J. 1965. O gênero Psammolestes Bergroth, 1911, com um estudo sôbre as genitálias das espécies (Hemiptera, Reduviidae, Triatominae). Revista Brasileira de Biologia 25:344-376.

1969. O gênero Rhodnius Stål,1858 com estudo sobre a genitália das espécies (Hemiptera - Reduviidae - Triatominae). Revista Brasileira de Biologia 29:487-560.

1970. O gênero Eratyrus Stål, 1859 com um estudo sobre a genitália externa (Hemiptera, Reduviidae, Triatominae). Revista Brasileira de Biologia 30:297-312.

Lent, H. \& Wygodzinsky, P. 1979. Revision of the triatominae (Hemiptera, Reduviidae), and their significance as vectors of Chagas' disease. Bulletim of American Museum of Natural History 163:163-175.

Lima, A. C. 1940 Insetos do Brasil, Hemípteros. Escola Nacional de Agronomia, série didática. v.2, 351p.

Mascarenhas, B. M. 1987. Descrição dos estádios imaturos de Rhodnius brethesi Matta, 1919 (Hemiptera, Reduviidae). Boletim do Museu Paraense Emilio Goeldi Seção Zoologia 3:183-194.

Mejia, J. M.; Galvão, C. \& Jurberg, J. 1999. Rhodnius colombiensis sp. n. da Colômbia, com quadros comparativos entre estruturas fálicas do gênero Rhodnius Stål, 1859 (Hemiptera, Reduviidae, Triatominae). Entomologia y Vectores 6:601-617.

Perlowagora-Szumlewicz, A. \& Cruz, H. N. 1972. Triatominae (Hemiptera, Reduviidae): sex identification in immature forms of vectors Chagas disease. Revista do Instituto de Medicina Tropical de São Paulo 14:6-11.

Rocha, D. S.; Jurberg, J. \& Galvão, C. 1996. Descrição de ovos e ninfas de Triatoma lecticularia (Stäl, 1859) (Hemiptera, Reduviidae, Triatominae). Entomología y Vectores 3:123135 .

Schofield, C. J. 1998. Biosystematics of the Triatominae. In: M. W. Service ed. Biosystematics of Haematophagous insects. Oxford, Claredon. p.286-312.

Sherlock, I. A.; Carcavallo, R. U. \& Galíndez-Girón, I. 1998. List of natural and experimental flagella infections several Triatominae species. In: Carcavallo, R. U.; Galíndez Girón, I.; Jurberg, J. \& Lent, H. eds. Atlas dos vetores da doença de Chagas nas Américas. Rio de Janeiro, Editora FIOCRUZ. v.1, p.289-298.

Silva, M. B. A.; Barbosa, H. S.; Carcavallo, R. U.; Galvão, C. \& Jurberg, J. 1999. Placas apicais do lábio das ninfas de $1^{\circ}$ estádio de Triatoma guazu Lent \& Wygodzinsky, 1979 e Triatoma jurbergi Carcavallo, Galvão \& Lent, 1998 (Hemiptera, Reduviidae), vetores da doença de Chagas. Entomología y Vectores 6:663-668.

Silva, M. B. A.; Barbosa, H. S.; Galvão, C.; Jurberg, J. \& Carcavallo, R. U. 2003. Comparative Study of the Stridulatory Sulcus, Buccula and Rostrum of the Nymphs of Triatoma guazu Lent \& Wygodzinsky, 1979 and Triatoma jurbergi Carcavallo, Galvão \& Lent, 1998 by Scanning Electron Microscopy (Hemiptera, Reduviidae). Memórias do Instituto Oswaldo Cruz 98:335-344.

Silva, M. B. A.; Barbosa, H. S.; Jurberg, J.; Galvão, C. \& Carcavallo, R. U. 2002. Comparative ultrastructural analysis of the antennae of Triatoma guazu and Triatoma jurbergi during the nymphal stage development (Hemiptera, Reduviidae). Journal of Medical Entomology 39:705-715.

Silva, M. B.; Jurberg, J.; Barbosa, H. S.; Rocha, D. S.; Carcavallo, R. U. \& Galvão, C. 2005. Comparative morphology of eggs and nymphs of Triatoma vandae Carcavallo, Jurberg, Rocha, Galvão, Noireau \& Lent, 2002 and Triatoma williami Galvão, Souza \& Lima, 1965. Memórias do Instituto Oswaldo Cruz 100:549-61.

Silva, M. B. A.; Jurberg, J.; Galvão, C.; Barbosa, H. S. \& Carcavallo, R. U. 1998. Same insuficiently know cuticular structures of 
the Triatoma guazu Lent \& Wygodzinsky, 1979. Memórias do Instituto Oswaldo Cruz 93(suppl. II): 345.

Silva, M. B. A.; Jurberg, J.; Galvão, C. \& Carcavallo, R. U. 2000. Estudo morfológico e morfométrico de ovos e ninfas de Triatoma guazu Lent \& Wygodzinsky, 1979 (Hemiptera,
Reduviidae, Triatominae) vistos por microscopia óptica e eletrônica de varredura. Entomología y Vectores 7:311334.

Tonn, R. J. 1988. Potential for research on vectors of Chagas' disease. Revista Argentina de Microbiología 20:1-3. 